\title{
Sexual behaviour and correlates for risky sexual behaviour among youth attending government vocational training institutes in Colombo District \\ Siriwardena $\mathrm{LN}^{1}$, Abeygunasekera $\mathrm{N}^{2}$
}

\begin{abstract}
Background: Youth represent a proportion of the population most exposed to Sexually Transmitted Infections. The study of sexual behaviour patterns and what factors predisposes them for risky sexual behaviour is important in designing targeted interventions for youth.

Objective: To describe socio demographic profile, knowledge on STI, HIV and sexual health and information sources, sexual behaviour and correlates for risky sexual behaviour among youth aged 18-24 years in government vocational training institutes in Colombo District.

Method: Calculated sample size was 420. Stratified random sampling was used to enroll participants. Data was collected through a self-administered questionnaire. Data was analyzed using percentages, chi square test and logistic regression.

Results: Just over half (52\%) the sample were males and all had completed Ordinary level examination or beyond. Twenty-five percent of the respondents were sexually active. Nearly $69 \%$ had not used a condom at their last sex. Ten percent of males who were sexually experienced had anal sex at their first sexual exposure. Gender, ability to earn, knowledge on STI prevention and contraception, using pornography in the last 12 months and social media to find partners were associated with ever having sex. Male sex and ability to earn were positive predictors of ever having sex and contraceptive knowledge was a negative predictor.
\end{abstract}

Conclusions: Risky pre-marital sex is present among this study sample. Male sex and ability to earn were positively predictive of ever having sex. Knowledge on contraception was negatively predictive.

Key words: risky sexual behaviour, youth

Authors: corresponding author; ${ }^{1}$ Siriwardena $L N^{1},{ }^{1}$ Acting Consultant Venereologist, STD clinic, Homagama, Sri Lanaka, Email: lasanthi_gunaratne@hotmail.com

${ }^{2}$ Abeygunasekera N, Consultant Venereologist, STD Clinic, Kalubowila, Sri Lanka

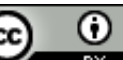

Acknowledgement: All the participants in the study, my colleagues who helped in this study-Dr.Ajith Karawita, Dr. Dharashanie Wijewickreme, Dr. Nimali Widanage

Conflict of interest: Authors claim no conflicts of interest, Funding: not funded, Originality: This is an original work which has been not published anywhere else 


\section{Full article}

\section{Introduction}

Youth represent a proportion of the population most exposed to Sexually Transmitted Infections (STIS) due to sexual discovery and initiation. Their eventual engagement in risky sexual behaviour, make them vulnerable to acquire STIs and HIV and unwanted pregnancies.

Behaviours that put an individual at risk of sexually transmitted infections, HIV or unwanted pregnancy are identified as risky sexual behaviour. Early sexual initiation is a known risk factor for all of the above unwanted sexual health outcomes. This vulnerability is due to biological, anatomical and psychosocial factors associated with young age. ${ }^{1}$ Unprotected (without a condom) anal, vaginal and oral intercourse is a well-known risk factor for HIV and STIs. Even oral - anal contact without a barrier is known to transmit infection. Incorrect, inconsistent and non-use of condoms during sexual intercourse is a known risk factor for HIV, STI and unplanned pregnancies. ${ }^{2}$ Having multiple concurrent partners is also a well-known risk for HIV and STIs. ${ }^{3}$

HIV annual data for Sri Lanka over the past few years show more HIV infections among the 1524year age group, and HIV transmission through homosexual intercourse is on the rise. ${ }^{4}$ Their risk for acquiring HIV is closely related to their sexual behaviour and other risk behaviour. As youth sexual behaviour has not been captured in the national demographic and health survey and the past two BSS (Biologcal and sero surveillance) and IBBS (Integrated Biological and Behaviour Surveillence) adequate information is not available for targeted interventions. Provision of sexual health services to meet the needs of the population requires a measure of understanding of all the elements of sexual health. Therefore, these changing dynamics of HIV epidemiology warrant the need to study sexual behaviour patterns of the youth of today. It is also important to know what factors predisposes them towards risky sexual behaviour.
In Sri Lanka, approximately 35,000 youth get vocational education and training annually through a network of training centers under the Ministry of Youth and Skills Development, the largest training network for vocational training. Nearly 16,000 of the youth enrolled are found in training centers within the district of Colombo.

This study was done to look at sexual behaviour and correlates for risky sexual behaviour among youth aged 18-24 years attending vocational training centers under the Ministry of Youth and Skills Development in the district of Colombo.

\section{Methods}

This was a descriptive cross sectional study carried out in vocational training centers under the Ministry of Youth and Skills Development in the district of Colombo. Calculated sample size was 420 . There were 27 vocational training centers under 6 institutes in Colombo District. It was assumed that the behaviour patterns with regard to sexual and reproductive health were homogeneous across all institutes. The number of students enrolled at these vocational training centers at the time of the study was 15,942 . The sampling frame was students aged 18-24 years enrolled across the 6 institutes. The sample size was then distributed proportionate to the required age group student population, enrolled under each institute. The participants were selected randomly from student registers in each vocational training center. A total of 415 students that fulfilled the inclusion criteria completed the questionnaire and the respondent rate was $98.6 \%$. New recruits and part time students were excluded from the study.

In this study risky sexual behaviour was said to be present if the participants were having one of the following exposures.

a) penetrative oral, vaginal or anal intercourse or attempt with close genital contact

b) Sex without condoms at last sex

c) Having more than one sexual partner within the last 3 months 
Data was collected through a self-administered pre tested questionnaire and the data was analyzed using SPSS version 17 .

All categorical variables were analyzed for counts and percentages. Level of knowledge was scored by giving 1 point for the correct response and 0 to incorrect or don't know responses. Cut off scores for level of knowledge was worked out by using the interquartile range for the scores. To ascertain the association and correlation between risky sexual behaviour, chi square and binary logistic regression was performed, with Hosmer Lemshow goodness of fit, with backward elimination to test for model fitness. Variables with $p$ value of $<0.05$ were considered statistically significant.

\section{Results}

Majority of the participants (51\%) were in the 18-20-year category and 52\% were males. Nearly $89 \%$ had completed advance level or above in education. Majority (98\%) were never married. Over $87 \%$ of them were financially dependent.

Ninety-six percent of the respondents said that they have heard of Sexually Transmitted Infections (STI). Majority (70-80\%) had satisfactory or above knowledge on STIs and HIV.

Table 1: Frequency distribution of socio demographic characteristics of the study sample

\begin{tabular}{|c|c|c|c|}
\hline Category & Sub-category & $\begin{array}{r}\text { Coun } \\
t\end{array}$ & $\begin{array}{l}\text { Perce } \\
\text { nt (\%) }\end{array}$ \\
\hline \multirow{3}{*}{$\begin{array}{l}\text { Age in } \\
\text { years } \\
(n=412)\end{array}$} & $18-20$ & 213 & 51.3 \\
\hline & $21-24$ & 199 & 48.0 \\
\hline & Total & 412 & 100.0 \\
\hline \multirow{3}{*}{$\begin{array}{l}\text { Sex } \\
(n=414)\end{array}$} & Female & 198 & 47.8 \\
\hline & Male & 216 & 52.2 \\
\hline & Total & 414 & 100.0 \\
\hline \multirow{9}{*}{$\begin{array}{l}\text { Province } \\
\text { of } \\
\text { residence } \\
(n=408)\end{array}$} & Western & 359 & 88.0 \\
\hline & Southern & 13 & 3.2 \\
\hline & Sabaragamuwa & 13 & 3.2 \\
\hline & North western & 8 & 2.0 \\
\hline & Central & 7 & 1.7 \\
\hline & Uva & 3 & 0.7 \\
\hline & Northern & 3 & 0.7 \\
\hline & Northcentral & 1 & 0.2 \\
\hline & Eastern & 1 & 0.2 \\
\hline
\end{tabular}

\begin{tabular}{|c|c|c|c|}
\hline & Total & 408 & 100.0 \\
\hline \multirow{6}{*}{$\begin{array}{l}\text { Level of } \\
\text { Education } \\
\text { completed } \\
(n=411)\end{array}$} & Completed A/L & 244 & 58.8 \\
\hline & $\begin{array}{l}\text { Completed } \\
\text { certificate/techni } \\
\text { cal course }\end{array}$ & 79 & 19.2 \\
\hline & Completed O/L & 46 & 11.2 \\
\hline & $\begin{array}{l}\text { Completed } \\
\text { Diploma }\end{array}$ & 39 & 9.5 \\
\hline & Other & 3 & 0.7 \\
\hline & Total & 411 & 100.0 \\
\hline \multirow[t]{4}{*}{$\begin{array}{l}\text { Civil status } \\
(n=408)\end{array}$} & $\begin{array}{ll}\text { Single } & \text { (never } \\
\text { married) } & \end{array}$ & 399 & 97.8 \\
\hline & Married & 8 & 2.0 \\
\hline & $\begin{array}{l}\text { Living together } \\
\text { not married }\end{array}$ & 1 & 0.2 \\
\hline & Total & 408 & 100.0 \\
\hline \multirow{3}{*}{$\begin{array}{l}\text { Financial } \\
\text { dependen } \\
\text { cy }(n=405)\end{array}$} & Yes & 354 & 87.4 \\
\hline & No & 51 & 12.6 \\
\hline & Total & 405 & 100.0 \\
\hline
\end{tabular}

Table 2: Frequency distribution of level of knowledge on STIs, STI prevention and HIV

\begin{tabular}{|c|c|c|c|}
\hline $\begin{array}{l}\text { Knowledge } \\
\text { component }\end{array}$ & Indicator & Count & Percent \\
\hline \multirow[t]{4}{*}{ STI } & Poor & 91 & 22.9 \\
\hline & Satisfactory & 226 & 56.9 \\
\hline & Good & 80 & 20.2 \\
\hline & Total & 397 & 100.0 \\
\hline \multirow{4}{*}{$\begin{array}{l}\text { STI } \\
\text { prevention }\end{array}$} & Poor & 31 & 7.9 \\
\hline & Satisfactory & 328 & 83.2 \\
\hline & Good & 35 & 8.9 \\
\hline & Total & 394 & 100.0 \\
\hline \multirow[t]{4}{*}{ HIV } & Poor & 90 & 23.1 \\
\hline & Satisfactory & 244 & 62.7 \\
\hline & Good & 55 & 14.1 \\
\hline & Total & 389 & 100.0 \\
\hline
\end{tabular}

Forty percent of the participants could not name a scientific method of contraception. Nearly $60 \%$ of those who were not aware of scientific methods of contraception were females.

Health services was the common source of information for STIs and contraception (30\%). Internet was also a preferred source (13\% for STIs and $16 \%$ for contraception) of information.

Nearly $50 \%$ of the participants did not consider the sexual and reproductive health (SRH) education provided in school as sufficient and over $50 \%$ considered that school SRH education did not prepare them for their 
sexual debut, or to avoid STIs or unplanned pregnancies.

Nearly quarter (25\%) were sexually active and $43 \%$ of them had had their sexual debut before the age of 18 years. Ninety-three percent of those who were sexually experienced were not married. Sixty percent of those who were sexually experienced had not used condoms at their sexual debut and another $14 \%$ could not remember if they had. Nearly $69 \%$ had not used a condom at their last sex. Commonest sexual behaviour for sexual debut was oral sex for both males (74\%) and females (59\%).Ten percent of males who were sexually experienced had anal sex at their first sexual exposure.

Table 3: Frequency distribution of ever having sex and characteristics of first sex

\begin{tabular}{rr} 
Frequency $(\mathrm{N})$ & \multicolumn{2}{c}{ Percentage (\%) } \\
\hline Male Female Total & Male Female Total
\end{tabular}
Have you ever had vaginal, anal or oral intercourse with someone? $(n=383)$

\begin{tabular}{|c|c|c|c|c|c|c|}
\hline Yes & 73 & 22 & 95 & 35.8 & 12.4 & 24.8 \\
\hline No & 131 & 156 & 288 & 64.2 & 87.6 & 75.2 \\
\hline Total & 204 & 178 & 383 & 100.0 & 100.0 & 100.0 \\
\hline \multicolumn{7}{|c|}{ Civil status ( $n=95)$} \\
\hline $\begin{array}{l}\text { Single/Never } \\
\text { married }\end{array}$ & 73 & 14 & 87 & 100.0 & 63.6 & 92.6 \\
\hline Married & 0 & 8 & 8 & 0 & 34.4 & 8.4 \\
\hline Total & 73 & 22 & 95 & 100.0 & 100.0 & 100.0 \\
\hline \multicolumn{7}{|c|}{ Age at first sex $(n=93)$} \\
\hline $\begin{array}{l}18 \text { years or } \\
\text { below }\end{array}$ & 35 & 5 & 40 & 46.6 & 23.8 & 43.0 \\
\hline$>18$ years & 37 & 16 & 53 & 52.4 & 76.2 & 57.0 \\
\hline Total & 72 & 21 & 93 & 100.0 & 100.0 & 100.0 \\
\hline \multicolumn{7}{|c|}{ First sex exposure (multiple responses possible) } \\
\hline Vaginal & 22 & 7 & 29 & 30.1 & 31.8 & 30.5 \\
\hline Anal & 7 & 11 & 8 & 9.6 & 4.5 & 8.4 \\
\hline Oral & 54 & 13 & 67 & 74.0 & 59.1 & 70.5 \\
\hline Other & 4 & 0 & 4 & 5.5 & 0 & 4.2 \\
\hline
\end{tabular}

Subsequent sexual behaviour following the sexual debut was analyzed for only those who were not married and sexually experienced. One tenth of sexually active males had male partners in the last 12 months but only $2 \%$ had engaged in anal sex during the last 12 months. Half the proportion of females who had ever had sex and almost all the males who had ever had sex (98\%) had sexual partners in the last 12 months and $7 \%$ of them had more than one sexual partner within the last 3 months.

The commonest last sexual exposure for unmarried males was cunnilingus (38\%), followed by vaginal sex (30\%) and fellatio (27\%). For unmarried females the last sexual exposure patterns was mainly fellatio and cunnilingus $(88 \%)$ and one participant had engaged in anal sex. Majority (69\%) of the participants had not used a condom at their last sexual exposure.

Table 4: Frequency distribution of type of last sexual exposure for males and females who were not married

\begin{tabular}{|c|c|c|c|c|}
\hline & & Indicator & Count & Percent \\
\hline \multirow{10}{*}{$\begin{array}{l}\text { what kind } \\
\text { of sexual } \\
\text { exposures } \\
\text { did you } \\
\text { have the } \\
\text { last time } \\
\text { you had } \\
\text { sex }\end{array}$} & \multirow[t]{6}{*}{ Males } & Oro-vaginal sex & 24 & 38.1 \\
\hline & & Oro-anal sex & 2 & 3.2 \\
\hline & & Oro-penile sex & 17 & 27.0 \\
\hline & & Peno-vaginal sex & 19 & 30.2 \\
\hline & & Peno-anal sex & 1 & 1.6 \\
\hline & & Total & 63 & 100.0 \\
\hline & \multirow[t]{4}{*}{ Female } & Oro-vaginal sex & 3 & 37.5 \\
\hline & & Oro-penile sex & 4 & 50.0 \\
\hline & & Peno-anal sex & 1 & 12.5 \\
\hline & & Total & 8 & 100.0 \\
\hline \multirow{3}{*}{\multicolumn{2}{|c|}{$\begin{array}{l}\text { Condom use at last } \\
\operatorname{sex}(n=74)\end{array}$}} & Yes & 23 & 31.1 \\
\hline & & No & 51 & 68.9 \\
\hline & & Total & 74 & 100.0 \\
\hline
\end{tabular}

Only $8 \%$ and $6 \%$ of those who were sexually active were under the influence of drugs or alcohol at the time of last sex. Thirteen percent had paid money for sex and nearly half of that had received gifts or money for sex sometime in their life. Nearly $5 \%$ of those who ever had sex had sex without consent ever in their life. More than half the study population had watched pornography (54\%) in the last 12 months and $18 \%$ had used social media to seek partners in the last 12 months.

Table 5: Use of pornography and social media to find partners among the study sample in the last 12 months

\begin{tabular}{llrr}
\hline & Indicator & Count & Percent \\
\hline Have you watched & Yes & 169 & 54.2 \\
\cline { 2 - 4 } $\begin{array}{l}\text { pornography during } \\
\text { the last 12 months? }\end{array}$ & No & 143 & 45.8 \\
\cline { 2 - 4 }$(\mathrm{n}=312)$ & Total & 312 & 100.0 \\
\hline $\begin{array}{l}\text { Have you used social } \\
\text { media to seek }\end{array}$ & Yes & 56 & 18.1 \\
\cline { 2 - 4 } $\begin{array}{l}\text { partners in the last } \\
12 \text { months? }(\mathrm{n}=309)\end{array}$ & No & 253 & 81.9 \\
\cline { 2 - 4 } & Total & 309 & 100.0 \\
\hline
\end{tabular}

There was very strong evidence of association between gender $\left(x^{2}=38.743\right.$ with $\left.1 d f ; P<0.001\right)$, ability to generate and income $\left(x^{2}=15.952\right.$ with $1 d f ; \quad P<0.001)$, STI prevention knowledge 
$\left(x^{2}=11.024\right.$ with $\left.2 d f ; P<0.001\right)$, contraceptive knowledge $\left(x^{2}=30.127\right.$ with $\left.4 d f ; P<0.001\right)$ use of pornography in the last 12 months $\left(x^{2}=28.236\right.$ with $\left.1 d f ; P<0.001\right)$ and use of social media to seek partners in the last 12 months and ever having sex $\left(x^{2}=6.012\right.$ with $1 d f$; $P=0.014$ ).

Table 6: Association of sociodemographic characteristics, STI/HIV and contraceptive knowledge and behaviour factors of youth against ever having sex

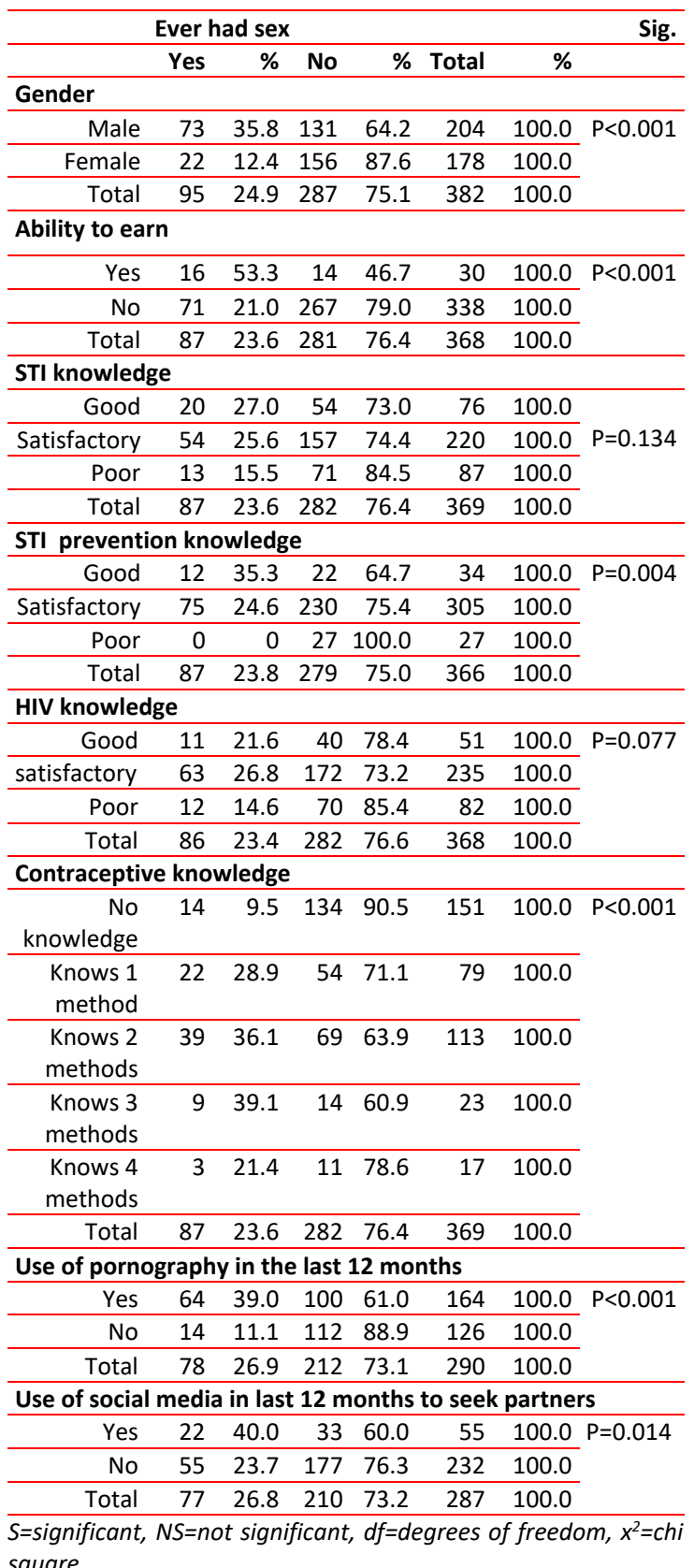

When multivariate logistic regression analysis was done male sex, ability to earn and having knowledge on contraception were predictors of ever having sex amongst this study population. Male gender was 1.56 times more likely to have had penetrative sex and ability to earn was 1.1 times predictive towards engaging in penetrative sex and having knowledge on contraception methods was 1.36 times less predictive towards engaging in penetrative sex.

\section{Discussion}

Risky pre marital sexual behaviour was seen in this youth sample despite being exposed to school sexual and reproductive health education and satisfactory knowledge on STIS and HIV. The percentage who were sexually active in this youth group were similar to other studies conducted among university students and national youth corps trainees in Sri Lanka. ${ }^{5,6}$ Of those who ever had sex, $43 \%$ has had their sexual debut at or before 18 years. In contrast, in the study conducted amongst new recruits of Youth Corps $64 \%$ of the sample has had sex at 18 years or below. ${ }^{5}$ This may have been due to the higher number of early school leavers in Youth corps.

Oral sex is commonly practiced among the participants. When asked about STI transmission through oral sex only $41 \%$ correctly said that STIs could be acquired through oral sex. The reason for oral sex being practiced commonly may be due to the belief that it is safer than vaginal or anal sex. Preference for oral sex among females who were not married and sexually active may also be due to socio cultural beliefs such as preserving virginity. Further, in depth studies are required to find out the reasons for the practice of oral sex among young people.

One tenth of the males in this study sample had anal sex in their sexual debut and one tenth of males had same sex partners in the last 12 months. However, only $2 \%$ had engaged in anal sex in the last 12 months. Same sex attraction was low among females and anal sex was also not common. As sexual behaviour studies among young people are scares in Sri Lanka comparability cannot be assessed.

Nearly $69 \%$ did not use a condom in their last pre marital sex. Condom use among these youth is very low in comparison to European 
studies. ${ }^{7}$ Oral sex being considered a safe sexual behaviour may have contributed to none use of condoms. However, this study did not look into barriers for condom use. Further studies are required to identify these barriers. More than half the sample had used pornography in the last 12 months and 18\% used social media to find partners. The impact of social media and pornography on young people's sexual health has not been studied in Sri Lanka. As use of pornography and social media is evident in this group of urban youth, studies on its impact has to be carried out in the future.

In multivariate logistic regression analysis male gender and financial independence was positively predictive of ever having sex and contraceptive knowledge was a negative predictor. HIV and STI knowledge was not predictive of ever having sex. This implies that youth SRH education has to be re-evaluated.

\section{Conclusion}

This study proves that risky pre marital sexual behaviours occur among youth aged 18-24 years in an urban setting. More in depth analysis is required into their prevailing sexual behaviour and barriers for condom use. School SRH has been insufficient in preparing them for their sexual debut or to avoid unwanted consequences of sex. Satisfactory knowledge on STIs and HIV per say is not protective. A knowledge on contraceptive use is protective. $\mathrm{SRH}$ education and messages have to be more targeted and health care services and internet has to be utilized in targeted interventions. The impact of pornography and utilization of social media for SRH needs in youth is a new area that has to be evaluated.

\section{References}

1. Qiaqin $M$, Kihara MO, Cong L, Xu G, Xiaohong $P$, Zamani S, Ravari SM, Zhang D, Homma T, Kihara M. Early initiation of sexual activity: risk factor for sexually transmitted diseases, HIV infection, and unwanted pregnancy among university students in China. BMC Public Health 2009;9(111).

2. Alford S. Condom Effectiveness. Advocates for youth 2005.

3. Mishra V,Van Assche B. Concurrent sexual partnerships and HIV infection: Evidence from National Population Based Surveys. DHS working papers 2009.
4. National STD AIDS Control Programme. Annual Report 2016. 2016.

5. Vidhanapathirana J, Wijegoonewardhana N, Fernando $M$, Nawarathna $S$, Suranga MA, Premachandra M. Evidence on the knowledge and attitudes of Sri Lankan youth on sexual and reproductive health and their current sexual practices. National STD AIDS Control Programme; 2019. p. 1-46.

6. Perera UAP, Abeysena C. Prevalence and associated factors of risky sexual behaviors among undergraduate students in state universities of Western Province in Sri Lanka: a descriptive cross sectional study. Reproductive Health. 2018;15(1):105.

7. Miranda PSF, Aquino JMG, Monteiro R, Dixe M, Luz A, Moleiro P. Sexual behaviors: study in the youth. Einstein (Sao Paulo, Brazil). 2018;16(3):eAO4265. 